\title{
Undetected viral infection in diffuse alveolar damage associated with bone marrow transplantation
}

\author{
J.A. Barberà, J.M. Martín-Campos, T. Ribalta, E. Carreras, A. Llopart, \\ J. Sierra, C. Rozman, R. Rodríguez-Roisin
}

Undetected viral infection in diffuse alveolar damage associated with bone marrow transplantation. J.A. Barberà, J.M. Martín-Campos, T. Ribalta, E. Carreras, A. Llopart, J. Sierra, C. Rozman, R. Rodríguez-Roisin. CERS Journals Ltd 1996.

ABSTRACT: To investigate the presence of nondiagnosed viral lung infections in patients who developed acute respiratory failure and diffuse pulmonary infiltrates after bone marrow transplantation (BMT), we studied necropsy-obtained lung specimens with features of diffuse alveolar damage (DAD) where no other specific histological diagnosis could be established, by using in situ hybridization and immunohistochemistry.

Lung tissue samples obtained at necropsy from 19 patients ( 12 males and 7 females; $31 \pm 11$ yrs mean \pm SD age) who died $56 \pm 36$ days after BMT (12 allogeneic and 7 autologous), were studied retrospectively using specific deoxyribonucleic acid (DNA) probes to detect cytomegalovirus (CMV), herpes simplex virus (HSV), Epstein-Barr virus (EBV), and adenovirus genomes. Tissue samples were additionally processed with antibodies to CMV and HSV antigens.

Cells infected by CMV were detected by in situ hybridization in five cases, and by immunohistochemistry in four cases. Combining the results of both procedures, a previously undiagnosed CMV infection was found in six patients. All of them had received an allogeneic BMT and had developed graft-versus-host disease (GVHD). No evidence of cells infected by HSV, EBV, or adenovirus was found in any case. No viral infection was detected either in recipients of autologous marrow or in recipients of allogeneic BMT without GVHD.

These results indicate that pulmonary cytomegalovirus infection not detected by conventional histological examination may be present in patients with diffuse alveolar damage associated with bone marrow transplantation, especially in recipients of allogeneic marrow who develop graft-versus-host disease. Furthermore, the use of in situ hybridization and/or immunohistochemistry on pulmonary histology might improve the diagnosis of viral lung infections in patients receiving bone marrow transplantation.

Eur Respir J., 1996, 9, 1195-1200.
Serveis de Pneumologia i Al.lèrgia Respiratòria, Anatomia Patològica i Hematologia, Hospital Clínic, Departament de Medicina, Universitat de Barcelona, Spain.

Correspondence: J.A. Barberà

Servei de Pneumologia i Al.lèrgia Respiratòria Hospital Clinic

Villarroel 170

08036-Barcelona

Spain

Keywords: Cytomegalovirus

herpes simplex virus

immunohistochemistry

nucleic acid hybridization

pneumonia

Received: May 161995

Accepted after revision February 151996

Supported by Grants 92/0103 and 95/0257 from the Fondo de Investigaciones Sanitarias (FIS), SEPAR/1990 from the Sociedad Española de Neumología y Cirugía Torácica, JCIF/P-CR from the José Carreras International Foundation, and GRQ 94-9103 from the Comissionat per Universitats i Recerca de la Generalitat de Catalunya.
Pulmonary complications account for significant morbidity and mortality after bone marrow transplantation (BMT) [1]. Pneumonia of bacterial, viral or fungal origin is the most frequent complication, as a consequence of the altered immunological status of the host [2]. Nevertheless, approximately $12 \%$ of BMT recipients develop diffuse radiographic lung infiltrates without evidence of active lower respiratory tract infection [2], a condition that has been named "idiopathic pneumonia syndrome" [3]. In some instances, patients with idiopathic pneumonia may develop progressive respiratory failure needing mechanical ventilation, a situation that entails very poor outcome [4-6]. Open lung biopsy and postmortem studies in such cases have revealed histological features of diffuse alveolar damage (DAD) with a high prevalence of cytomegalovirus (CMV) and fungal infections [5, 7]. However, in a substantial number of cases, no specific infectious agents can be identified with conventional histological techniques and the aetiology of the process remains undetermined.

In situ hybridization using biotinylated probes is a useful tool for the identification of specific viral nucleic acids in formalin-fixed, paraffin-embedded tissue samples [8]. Immunohistochemistry using antibodies to viral antigens also allows the detection of viral infection in tissue sections [9]. The use of these techniques might be of help in detecting previously undiagnosed viral infections in cases with idiopathic pneumonia. Accordingly, the present study was addressed to investigate the presence of viral infections, by using both in situ hybridization and immunohistochemistry, in lung specimens from patients who died with histological features of DAD after BMT, and where no other specific diagnoses could be established by conventional histological examination.

\section{Methods}

\section{Patients and case material}

From the 56 autopsy studies performed in our institution between 1985 and 1993 in patients who died after BMT, we selected 19 cases (12 males and 7 females) with 
the histological diagnosis of DAD of undetermined aetiology. Clinical data from the patients were examined retrospectively from the hospital records, the major individual characteristics being listed in table 1 . Mean \pm SD age of the patients was $31 \pm 11$ yrs. Twelve patients had received an allogeneic transplant, and the remaining seven had received an autologous one. The pretransplant conditioning regimen performed in our institution has been reported previously [10]. Mean \pm SD survival after transplantation was $56 \pm 36$ days (range 17-154 days). All patients had developed diffuse radiographic infiltrates and respiratory failure, fulfilling the diagnostic criteria for acute lung injury (ALI) or acute respiratory distress syndrome (ARDS) [11], and received assisted mechanical ventilation for a mean of $9 \pm 6$ days before death. Cytomegalovirus (CMV) serological tests were performed in all cases by the complement-fixation antibody test, before and after BMT.

Fibreoptic bronchoscopy examination addressed to diagnose the aetiology of the pulmonary infiltrates had been performed in 13 patients. As reported in detail previously [12], in our institution bronchoscopic examination in immunosuppressed patients includes the microbiological investigation of protected specimen brushing and bronchoalveolar lavage (BAL) fluid with cultures in aerobic, anaerobic, and fungal media, as well as stains for Legionella pneumophila. Smears obtained by cytocentrifugation of BAL fluid are stained with the Ziehl-Neelsen, Giemsa periodic acid-Schiff (PAS), haematoxylin and eosin $(\mathrm{H}$ \& E), Perls' and methenamine-silver methods, and examined for the presence of fungal hyphae and yeasts, as well as for Pneumocystis carinii and viral inclusion bodies. In the present series, positive cultures were obtained in four cases (Candida albicans, Streptococcus viridans, Staphylococcus aureus and Pseudomonas maltophilia). In all cases, the cytological examination of BAL fluid was considered negative for the presence of CMV-associated cytopathic changes and viral inclusion bodies.

Lung specimens obtained at necropsy were fixed with $10 \%$ formalin, embedded in paraffin, and tissue sections 3-4 $\mu \mathrm{m}$ thick stained with $\mathrm{H} \& \mathrm{E}$. The diagnosis of DAD was established according to the criteria defined by KATZENSTEIN et al. [13]: 1) hyaline membrane formation; 2) hyperplasia of alveolar epithelial lining; 3) capillary congestion and alveolar haemorrhage; 4) interstitial and alveolar oedema; and, 5) desquamation of lining epithelium and macrophage infiltrate. Specifically, DAD was diagnosed if the first and two of the other four criteria were fulfilled. Cases where DAD was associated with a specific diagnosis, namely viral or fungal pneumonitis, as well as those with extensive pneumonia or alveolar haemorrhage, were excluded for the purposes of the present study. No evidence of viral inclusions or characteristic cytopathic changes were shown in any case. Furthermore, sections stained with Gram, PAS, methenamine silver, and Giemsa did not show specific infectious agents as a major cause of the extensive alveolar damage. Aerobic and anaerobic cultures of the lung samples were also negative. No cultures in viral media were performed in any case.

\section{In situ hybridization}

In situ hybridization studies were performed as described previously [14]. Briefly, tissue sections, placed on 3-aminopropyltriethoxysilane (Sigma Chemical, St. Louis, MO, USA) pretreated glass slides, were dewaxed with xylene, washed in methyl alcohol, air-dried, and incubated in pepsin solution $\left(4 \mathrm{mg} \cdot \mathrm{mL}^{-1}, 0.2 \mathrm{~N} \mathrm{HCl}\right)($ Sigma Chemical) for $15 \mathrm{~min}$. Each section was overlaid with 10 $\mu \mathrm{L}$ of hybridization solution $(50 \%$ deionized formamide (Fluka Chemical, Ronkonkoma, NY, USA), 10\% dextran sulphate (Pharmacia Biotech, Piscataway, NJ, USA), $2 \%$ standard sodium citrate (SSC), $250 \mu \mathrm{g} \cdot \mathrm{mL}^{-1}$ sonicated salmon sperm deoxyribonucleic acid (DNA) (Sigma Chemical) and $2 \mu \mathrm{g} \cdot \mathrm{mL}^{-1}$ biotin-labelled DNA probe), and heated at $90^{\circ} \mathrm{C}$ for $10 \mathrm{~min}$ to denature DNA.

Tissue sections were hybridized separately with the following biotinylated DNA probes: 1) CMV probe (Enzo Diagnostics, New York, NY, USA), consisting of a mixture of the 18 and $13.2 \mathrm{~kb}$ BamHI fragments of the CMV genome cloned into pIB176 and pUC18, respectively; 2) herpes simplex virus (HSV) probe (Enzo Diagnostics), consisting of a mixture of the 8 and $16 \mathrm{~kb}$ BamHI fragments of the HSV genome cloned into pBR322; 3) EpsteinBarr virus (EBV) probe (Enzo Diagnostics), consisting of the $3.1 \mathrm{~kb}$ BamHI region of the EBV genome, cloned into pUC18; and, 4) adenovirus probe (Enzo Diagnostics) prepared from the adenovirus 5 genome.

Tissue secretions and hybridization solution were allowed to hybridize for $5 \mathrm{~h}$ (when processed with the EBV probe) or overnight (the remaining probes) at $37^{\circ} \mathrm{C}$ in a moist chamber. After hybridization, sections were rinsed with phosphate-buffered saline (PBS)-0.5\% Triton X-100, blocked with $5 \%$ bovine serum albumin (BoehringerMannheim, Mannheim, Germany), and incubated in 1.5 $\mu \mathrm{g} \cdot \mathrm{mL}^{-1}$ streptavidin-alkaline phosphatase conjugate (Bethesda Research Laboratory, Paisley, Scotland). After sequential washes, the slides were incubated for colour development in $0.033 \%$ nitroblue-tetrazolium (Sigma Chemical) and $0.016 \%$ bromo-4-chloro-3-indolyl phosphate (Sigma Chemical), at room temperature in the dark for 30-40 min. Finally, the slides were rinsed in distilled water, air-dried, and mounted in Kaiser's glycerol jelly aqueous medium. Two blocks of tissue were examined in each patient.

Positive controls for the CMV probe consisted of lung tissue samples from five patients ( 3 males and 2 females; aged $31 \pm 10$ yrs) who died $77 \pm 16$ days after BMT, in whom CMV pneumonitis was diagnosed according to both the presence of viral inclusions and characteristic cytopathic changes on examination of HE stained tissue samples. Oesophageal and brain tissue samples with HSV infection served as positive controls of the HSV probe. Formalinfixed, paraffin-embedded Raji cells (American type culture collection (ATCC), Rockville, MD, USA) were used as positive controls of the EBV probe, and A549 cells infected with type 5 adenovirus (ATCC) of the adenovirus probe.

Lung tissue samples from eight patients who died after BMT with normal lungs on histological inspection were used as negative controls. Individual clinical characteristics of these patients are shown in table 1. Mean age ( $28 \pm 11 \mathrm{yrs})$ and survival after BMT $(88 \pm 100$ days) were similar to the patients who developed DAD ( $\mathrm{p}=0.45$ and $\mathrm{p}=0.40$, respectively; unpaired t-test). All of them had received an allogeneic BMT and their preparative regimen did not differ from that used in the study series.

A background control was additionally performed by hybridizing adjacent sections of each tissue sample with 


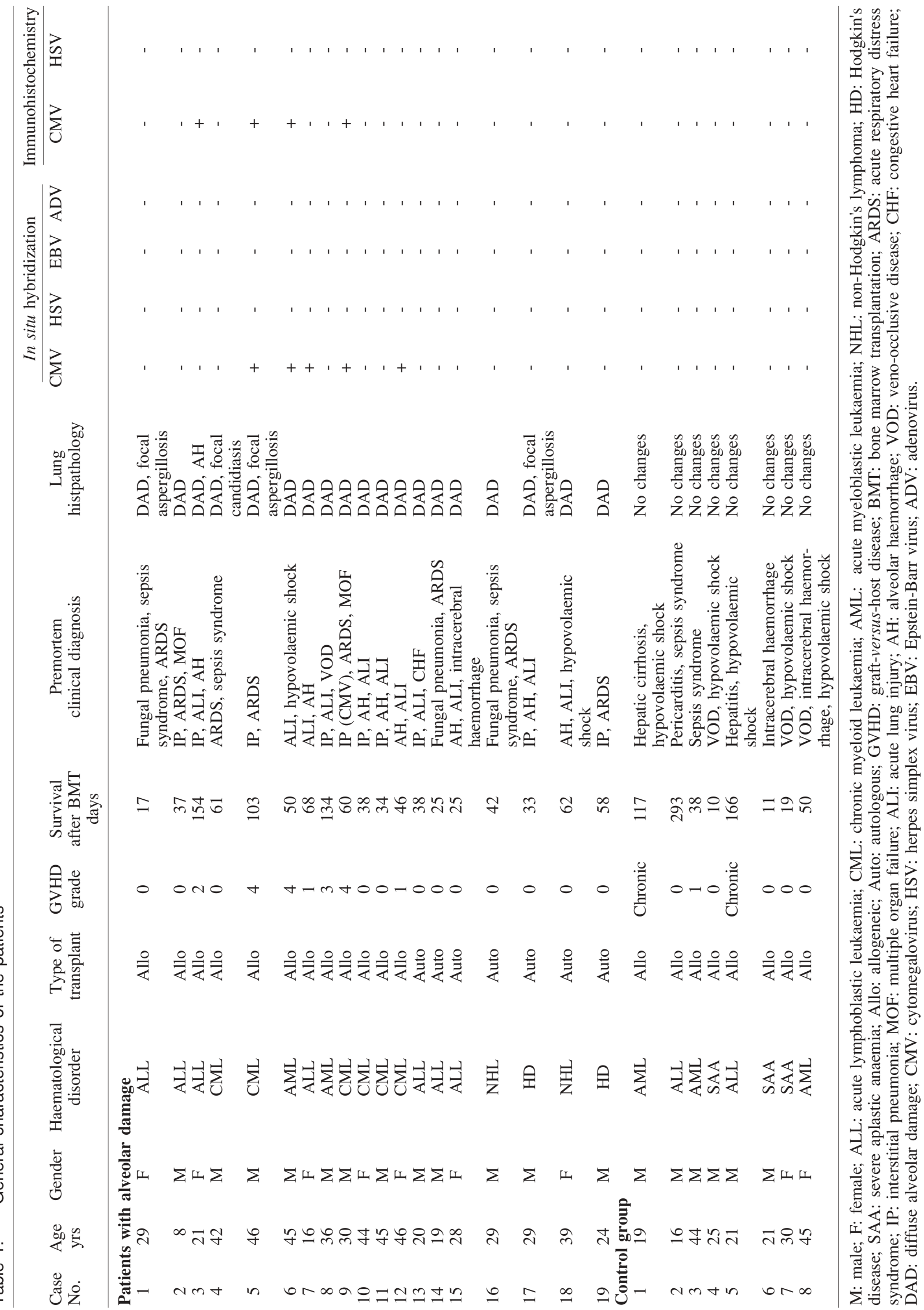


the pEMBL18+ cloning vector (Boehringer-Mannheim), that has strong homology with pIBI76 and pUC18 cloning vectors used in the CMV probe, and with pBR322 (Enzo Diagnostics), the cloning vector of the HSV probe, that also has strong homology with pUC18 cloning vector used in the EBV probe.

\section{Immunohistochemical studies}

Tissue sections were deparaffinized, treated with $3 \%$ hydrogen peroxide, preincubated with normal rabbit serum (Dako A/S, Glostrup, Denmark), and incubated with the primary antibodies. Two different antibodies were used: the monoclonal mouse anti-CMV early antigen (clone $\mathrm{CCH} 2$, Dako A/S), and the polyclonal rabbit anti-HSV type 1 -specific as well as anti-type common antigens (MacIntyre, Dako A/S), at a 1:50 dilution each. Subsequently, slides were incubated with biotinylated anti-mouse or anti-rabbit immunoglobulins. Detection was carried out with the avidin-biotin complex, revealed with chromogen diaminobenzidine, and lightly counterstained with haematoxylin.

\section{Results}

All patients had developed radiographic infiltrates and respiratory failure, fulfilling the criteria of ALI or ARDS [11], and were admitted to an intensive care unit, where assisted mechanical ventilation support was provided. Premortem clinical diagnoses of each patient are shown in table 1. Only one case No. (9) was diagnosed with CMV pneumonitis before death, on the basis of an increase in antibody titres, and was treated with ganciclovir. The examination of BAL fluid obtained in 13 patients was negative for $\mathrm{CMV}$-related cytopathological changes or viral inclusions. All patients had received broad spectrum antibiotic therapy, and five were treated empirically for CMV infection with either ganciclovir or foscarnet.

Histologically, all cases showed characteristic features of DAD [13], with extensive alveolar impairment (table

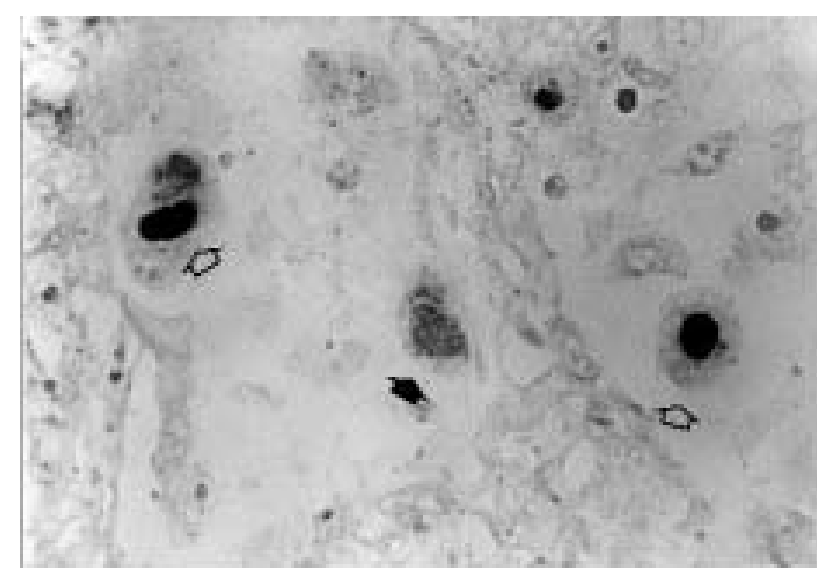

Fig. 1. - In situ hybridization with the cytomegalovirus (CMV) probe on lung tissue with histological features of diffuse alveolar damage (DAD) of unknown origin. Scattered cells show positive hybridization signals, disclosing a characteristic "nuclear pattern" (open arrows) or cytoplasmic inclusions (closed arrow). (No counterstain; magnification $\times 200$ )
1). In one case (No. 3) DAD was associated with areas of alveolar haemorrhage, and in four cases local foci of fungal infection were also noticed, although the circumscribed extension of the infiltrate did not suggest an invasive fungal infection as the source of DAD.

Individual results of in situ hybridization studies are shown in table 1 . Hybridization with the CMV probe disclosed the presence of cells bearing the CMV genome in five cases. Infected cells showed either a "nuclear pattern" with strong hybridization signal in the nucleus or multiple cytoplasmic inclusions (fig. 1). In most cases, however, only few CMV-infected cells localized within the alveolar spaces were observed on each tissue section, except in case No. 9, where numerous cells disclosing positive hybridization were apparent.

No hybridization with the CMV probe was found in the control group of six recipients of allogeneic marrow transplants with normal lungs, whereas it was clearly positive in the five control cases with evident viral inclusions on histological examination. Hybridization with the control pEMBL18+ cloning vector was negative in all cases.

Immunohistochemical analysis with the monoclonal antibody $\mathrm{CCH} 2$ to $\mathrm{CMV}$ antigens was positive in four cases of the study population (table 1), and in all positive control tissue samples. One case was positive with immunohistochemistry and negative with in situ hybridization, while the other three cases were positive with both techniques (table 1).

Whereas all cases with CMV infected cells had received an allogeneic BMT, no evidence of CMV infection was detected in the seven recipients of an autologous BMT (table 1). The incidence of CMV-infected cases among recipients of allogeneic transplants $(50 \%)$ was significantly different from that in recipients of autologous transplants and in negative control cases $(\mathrm{p}<0.05$ each; two-sided Fisher's exact test). Furthermore, all cases with positive CMV hybridization had developed graft-versus-host disease (GVHD), while no CMV infection was detected in patients without GVHD (table 1). The association between positive CMV DNA hybridization and GVHD was statistically significant $(\mathrm{p}<0.05$; two-sided Fisher's exact test).

No infected cells were detected when the tissue samples were hybridized with the specific probes for HSV, EBV and adenovirus DNA. In addition, no hybridization signals were detected in the group of bone marrow recipients with normal lungs when hybridized with these probes. In all the hybridization studies, both tissue samples and infected cells used as positive controls disclosed positive hybridization signals. Moreover, no positive signals were obtained with the use of the polyclonal antibody to HSV antigens.

\section{Discussion}

The present study shows that a previously undiagnosed CMV lung infection can be detected by using in situ hybridization and/or immunohistochemistry in patients dying with diffuse alveolar damage of undetermined aetiology after bone marrow transplantation. Furthermore, CMV infection was detected only in recipients of allogeneic marrow transplants with graft-versus-host disease but not in autologous BMT. 
We decided to investigate DAD because it is the most common histological diagnosis associated with respiratory failure and diffuse pulmonary infiltrates, being the histological counterpart of ARDS. The occurrence of DAD after BMT was already well-recognized $[3,7]$. Both interstitial pneumonitis and DAD are the two major histopathological patterns that have been identified in the idiopathic pneumonia syndrome. In our series of DAD diagnosed at necropsy, we were unable to identify histological characteristics of interstitial pneumonitis in any case.

The association between CMV infection and the development of interstitial pneumonitis after BMT is well-established $[1,2]$. Cytomegalovirus pneumonitis, as diagnosed by conventional histological criteria, accounts for $57 \%$ of cases in which diffuse pulmonary infiltrates develop following BMT [7]. In the present study, we identified CMV infection in 50\% of recipients of allogeneic marrow transplants with DAD by using both in situ hybridization and immunohistochemistry, where this infection had not been previously diagnosed at conventional histological examination. This suggests that CMV lung infection may be more prevalent than is commonly recognized. Occult viral infection that were subsequently identified by in situ hybridization or by DNA amplification using polymerase chain reaction (PCR) have been demonstrated previously. MYERSON and co-workers [15] reported two cases with disseminated CMV infection after BMT, diagnosed by in situ hybridization, where CMV DNA was identified in morphologically normal cells. Moreover, the same group of investigators [16] showed that in situ hybridization is as sensitive as viral culture in detecting CMV lung infection. Likewise, immunohistochemistry has a similar effectiveness for detecting CMV infection in paraffin tissue sections [9]. All these findings indicate that the diagnosis of CMV or other viral lung infections cannot be excluded solely on the basis of conventional histological examination, and that the use of nucleic acid hybridization or other sensitive techniques could enhance the diagnostic yield of the histological study in patients who develop pulmonary infiltrates after BMT. Moreover, since CMV lung infection entails a high mortality rate, efforts should be addressed to the early identification of this infection. In this regard, the use of newly developed techniques, such as rapid centrifugation viral culture [17], alveolar cell immunostaining [18], or PCR [19], in BAL fluid samples might be of help in the surveillance of BMT recipients [20]. The evaluation of BAL fluid limited to the characteristic cytopathic changes or viral inclusions has a low sensitivity for the detection of CMV infection [18], as it was the case in the present series.

In the in situ hybridization study, the intensity of the hybridization signal was less pronounced in the study cases, where the infection was not apparent at the conventional histological examination, than in control cases with evident cellular enlargement and intranuclear inclusions, suggesting a lower number of viral particles in cells that do not disclose characteristic cytopathic changes. This finding is consistent with the existence of different degrees of CMV infection in BMT recipients, ranging from latent infections in morphologically normal cells to replicative infections in cells with charcteristic cytopathology. Whereas an active CMV infection may result in severe DAD [21], it is unclear to what extent a latent infection may account for such a severe tissue damage. However, it has been suggested that abortively-infected cells can contribute to severe cellular dysfunction with little or no cytopathology [22]. Moreover, in many cases with evident CMV infection associated with DAD only few infected cells are detected, raising the question of whether the virus is solely responsible for the profound pulmonary alterations [23]. Experimental studies in mice have shown that a high rate of CMV replication is not a determinant of the severity of the associated pneumonitis [24]. Rather, it seems that CMV pneumonitis could have an immunopathological origin and that its severity may be related to an interplay between the viral infection and the host immune response [25]. In this regard, it is of interest to note that in our series all cases with positive CMV in situ hybridization and/or immunohistochemistry had received allogeneic marrow transplants and developed GVHD. By contrast, no CMV infection was detected among recipients of autologous marrow transplant, nor in recipients of allogeneic marrow who did not present GVHD. These findings are in agreement with the common association between GVHD and CMV pneumonitis $[10,26]$, and with the very low incidence of CMV pneumonia following autologous BMT [10, 27].

The results of the present study also rule out the relevance of other viral infections in the pathogenesis of DAD associated with BMT. Thus, we did not find any case with positive hybridization to HSV, adenovirus, and EBV DNA. This result is consistent with the experience previously reported at our institution, where only one case of HSV infection was identified among 58 episodes of interstitial pneumonitis [10]. Moreover, in biopsy or autopsy series reporting large number of patients who developed interstitial pneumonitis or diffuse lung infiltrates, HSV, adenovirus or respiratory syncytial virus infections have been identified only on very few occasions $[2,7]$, contrasting with the common occurrence of CMV infection [7]. Cone et al. [28] have recently reported a high prevalence of human herpes-virus 6 (HHV-6) infection in patients who develop interstitial pneumonitis after BMT, detected by PCR DNA amplification. Since, in our study, we did not test the specific viral genome we cannot exclude that HHV-6 could also be present.

In summary, the results of the present study show that a previously undiagnosed cytomegalovirus infection, as detected by in situ hybridization or immunohistochemistry, may be present in patients with diffuse alveolar damage occurring after bone marrow transplantation. Accordingly, such an infection may not be excluded solely on the basis of the absence of the characteristic histopathological changes. The incorporation of sensitive techniques to the study both of tissue sections and bronchoalveolar lavage fluid may help in assessing the actual incidence of cytomegalovirus infection among recipients of bone marrow transplantation. Moreover, we failed to demonstrate infections by herpes simplex virus, Epstein Barr virus or adenovirus, suggesting that these infections are uncommon in patients who develop radiographic infiltrates and respiratory failure following bone marrow transplantation. In this clinical condition, more efforts are needed to diagnose and treat early cytomegalovirus infections, particularly in recipients of allogeneic marrow transplants who develop graft-versus-host disease. 
Acknowledgements: The authors thank S. Hayashi (Pulmonary Research Laboratory, University of British Columbia, Vancouver, BC, Canada) for the gift of control cells, to A. Torres and A. Xaubet for their helpful comments, and to the technical staff of the Department of Pathology for their valuable assistance.

\section{References}

1. Krowka MJ, Rosenow III EC, Hoagland HC. Pulmonary complications of bone marrow transplantation. Chest 1985; 87: 237-246.

2. Wingard JR, Mellits D, Sostrin MB, et al. Interstitial pneumonitis after bone marrow transplantation. Medicine (Baltimore) 1988; 67: 175-186.

3. Clark JG, Hansen JA, Hertz MI, Parkman R, Jensen L, Peavy HH. Idiopathic pneumonia syndrome after bone marrow transplantation. Am Rev Respir Dis 1993; 147: 1601-1606.

4. Estopà R, Torres A, Kastanos N, Rives A, Agustì-Vidal A, Rozman C. Acute respiratory failure in severe hematologic disorders. Crit Care Med 1984; 12: 26-29.

5. Crawford SW, Hackman RC. Clinical course of idiopathic pneumonia after bone marrow transplantation. $\mathrm{Am}$ Rev Respir Dis 1993; 147: 1393-1400.

6. Paz HL, Crilley P, Weinar M, Brodsky I. Outcome of patients requiring medical ICU admission following bone marrow transplantation. Chest 1993; 104: 527-531.

7. Crawford SW, Hackman RC, Clarck JG. Open lung biopsy diagnosis of diffuse pulmonary infiltrates after marrow transplantation. Chest 1988; 94: 949-953.

8. Hogg JC. Application to pathology. In: Barnes PJ, Stockley RA, eds. Molecular Biology of Lung Disease. Oxford, Blackwell Scientific Publications, 1994; pp. 163-172.

9. Strickler JG, Manivel C, Copenhaver CM, Kubic VL. Comparison of in situ hybridization and immunohistochemistry for detection of cytomegalovirus and herpes simplex virus. Hum Pathol 1990; 21: 443-448.

10. Grañena A, Carreras E, Rozman C, et al. Interstitial pneumonitis after BMT: 15 years experience in a single institution. Bone Marrow Transplant 1993; 11: 453-458.

11. Bernard GR, Artigas A, Brigham KL, et al. and the Consensus Committee. The American-European consensus conference on ARDS: definitions, mechanisms, relevant outcomes, and clinical trial co-ordination. $\mathrm{Am}$ J Respir Crit Care Med 1994; 149: 818-824.

12. Xaubet A, Torres A, Marco F, Puig De la Bellacasa J, Faus R, Agustì-Vidal A. Pulmonary infiltrates in immunocompromised patients: diagnostic value of telescoping plugged catheter and bronchoalveolar lavage. Chest 1989; 95: $130-135$.

13. Katzenstein AA, Bloor CM, Liebow AA. Diffuse alveolar damage: the role of oxygen, shock and related factors. Am J Pathol 1976; 85: 210-224.
14. Barberà JA, Hayashi S, Hegel RG, Hogg JC. Detection of Epstein-Barr virus in lymphocytic interstitial pneumonia by in situ hybridization. Am Rev Respir Dis 1992; 145: 940-946.

15. Myerson D, Hackman RC, Nelson JA, Ward DC, McDougall JK. Widespread presence of histologically occult cyto-megalovirus. Hum Pathol 1984; 15: 430-439.

16. Myerson D, Hackman RC, Meyers JD. Diagnosis of cytomegaloviral pneumonia by in situ hybridization. $J$ Infect Dis 1984; 150: 272-277.

17. Crawford SW, Bowden RA, Hackman RC, Gleaves CA, Meyers JD, Clark JG. Rapid detection of cytomegalovirus pulmonary infection by bronchoalveolar lavage and centrifugation culture. Ann Intern Med 1988; 108: 180-185.

18. Emmanuel D, Peppard J, Stover D, Gold J, Armstrong D, Hamerling U. Rapid immunodiagnosis of cytomegalovirus pneumonia by bronchoalveolar lavage using human and murine monoclonal antibodies. Ann Intern Med 1986; 104: 476.

19. Cathomas G, Morris P, Pekle K, Cunningham I, Emanuel D. Rapid diagnosis of cytomegalovirus pneumonia in marrow transplant recipients by bronchoalveolar lavage using the polymerase chain reaction, virus culture, and the direct immunostaining of alveolar cells. Blood 1993; 81: 1909-1914.

20. Ljungman P, De Bock R, Cordonnier C, et al. Practices for cytomegalovirus diagnosis, prophylaxis and treatment in allogeneic bone marrow transplant recipients: report from the Working Party for Infectious Diseases of the EBMT. Bone Marrow Transplant 1993; 12: 399-403.

21. Craighead JE. Pulmonary cytomegalovirus infection in the adult. Am J Pathol 1971; 63: 487-504.

22. Southern P, Oldstone MBA. Medical consequences of persistent viral infections. N Engl J Med 1986; 314: 359-367.

23. Nash G. Pathologic features of the lung in the immunocompromised host. Hum Pathol 1982; 13: 841-858.

24. Shanley JD, Pesanti EL. The relation of viral replication to interstitial pneumonitis in murine cytomegalovirus lung infection. J Infect Dis 1985; 151: 454-458.

25. Grundy JE, Shanley JD, Griffiths PD. Is cytomegalovirus interstitial pneumonitis in transplant recipients an immunopathological condition? Lancet 1987; ii: 996-999.

26. Weiner RS, Horowitz MM, Gale RP, et al. Risk factors for interstitial pneumonia following bone marrow transplantation for severe aplastic anaemia. Br J Haematol 1989; 71: 535-543.

27. Jules-Elysee K, Stover DE, Yahalom J, White DA, Gulati SC. Pulmonary complications in lymphoma patients treated with high-dose therapy and autologous bone marrow transplantation. Am Rev Respir Dis 1992; 146: 485491.

28. Cone RW, Hackman RC, Wang MW, et al. Human herpesvirus- 6 in lung tissue from patients with pneumonitis after bone marrow transplantation. $N$ Engl $J$ Med 1993; 329: 156-161. 